\title{
MODELING AND CHARACTERIZATION OF NATURAL ORGANIC MATTER AND ITS RELATIONSHIP WITH THE THMS FORMATION
}

\author{
MISHRA B.K. ${ }^{1, *}$ \\ PRIYA T. ${ }^{1}$ \\ GUPTA S.K. \\ SINHA A.
}

\author{
${ }^{1}$ Department of Environmental Science and Engineering \\ Indian Institute of Technology, Dhanbad \\ Jharkhand-826004, India
}

Received: 04/02/2014

Accepted: 09/09/2016

*to whom all correspondence should be addressed:

Available online: $13 / 10 / 2016$ e-mail: bkmishra3@rediffmail.com

\section{ABSTRACT}

Natural organic matter (NOM) has been identified as the prominent precursor for disinfection by-products (DBPs) formation during chlorination. Various studies have suggests that the characteristics of NOM influence the Trihalomethanes (THMs) formation potential to the large extent. The present study represents the NOM characterisation in terms of total organic carbon (TOC), dissolved organic carbon (DOC), UV absorbance at $254 \mathrm{~nm}$ wavelengths $\left(\mathrm{UV}_{254}\right)$ and specific ultraviolet absorbance (SUVA) to investigate the effect of NOM on THMs formation mechanism. The high rate of dependency was observed for each representative of NOM with respect to water quality characteristics and operational condition of disinfection process. In this study, values of SUVA and $U_{254}$ have been drastically reduced with respect to variable chlorine dose which represent the significance of chlorine contact is more predominant with hydrophobic fractions of NOM. The value of SUVA is decreasing with respect to temperature and reaction time, which reveled higher rate of utilization for hydrophobic fractions of NOM. Predictive modeling approach was carried out using multiple regression analysis with the combination of two surrogates at each stage of modeling with help of operational condition of disinfection process and water quality characteristics. The $R^{2}$ value of the model was found in the range of 0.927 to 0.937 from the developed model and thus present model could be recommended for prediction of THMs in drinking water.

Keywords: Dissolved organic carbon, multiple linear regression, Natural organic matter, Specific ultraviolet absorbance, Total organic carbon, Trihalomethanes.

\section{Introduction}

Water quality has become an important outlet for human health and ecological system. During the periods of 4000 B.C. boiling was the most widely used process for water purification. Chemical disinfection for drinking water has been taken up at the beginning of the 20th century. The first application of chlorine disinfectants to water facilities was used in England during the period of 1890, followed by Middlekerke (Belgium) in the

Mishra B.K., Priya T., Gupta S.K. and Sinha A. (2016), Modeling and characterization of natural organic matter and its relationship with the THMs formation, Global NEST Journal, 18(4), 803-816. 
year 1902. The USA introduced chlorination of drinking water in Chicago and Jersey City in 1908 and Canada first started using chlorine for drinking water disinfection in Peterborough in 1916 (Chlorine Chemistry Council, 2003; Peterborough Utilities Commission, 1998). Chlorine dioxide is a strong water disinfectant over a wide $\mathrm{pH}$ range. It is more effective in killing bacteria and especially successful in deactivating viruses, due to its effectiveness against a broad range of pathogens, and provides a residual effect in the distribution system to prevent microbial re-growth. Chlorine is the most common disinfectant used worldwide (Trussell, 1993). However, chlorination of drinking water leads to formation of disinfection by products (DBPs) which may cause adverse health effects on human beings. During chlorination of water containing natural organic matter (NOM), a complex mixture of chlorine byproducts is formed and till now more than $\mathbf{3 0 0}$ different types of DBPs have been identified (Becher, 1999). The reactions between NOM and chlorine form different types of DBPs such as trihalomethanes (THMs); haloacetic acids (HAAs); haloacetonitriles (HANs), haloketones (HKs), aldehydes, carboxylic acids, nitrosamines and cyanogen halides. The epidemiological studies have indicated that exposure to these by-products increases the risk of bladder cancer, colon-rectum cancer, leukemia, stomach and rectal cancers as well as miscarriage, low birth weight, and birth defects (Mills et al., 1998; IARC, 1991; Calderon, 2000; Gallard and Gunten, 2002; Richardson et al., 2002; Villanueva et al., 2004). In 1986, as part of the Safe Drinking Water Amendments, the US Environmental Protection Agency (USEPA) proposed the Disinfectants/DBPs Rule Stage I \& II. Under Stage I, the maximum concentration level (MCL) for total THMs was set at $80 \mathrm{mg} \mathrm{l}^{-1}$ where as in Stage II, the MCL is expected to further decrease to $40 \mathrm{mg} \mathrm{I}^{-1}$ to reduce the level of risk potential of human health. (Pontius, 1999; Golfinopoulos and Arhonditsis, 2002).

Spectrum of disinfection byproducts mostly depends upon humic acid content,total organic carbon (TOC), quantity of inorganic chemicals in the water supply alongwith the reactions between chlorine and NOM during disinfection process, which are assumed to be major principal reaction pathways for the formation of DBPs in drinking water, and these reactions are influenced by the operational parameters $(\mathrm{pH}$, reaction time, disinfectant dose), environmental conditions (seasonal variability, water temperature) and water quality variables (type and amount of NOM, bromide ions) (Bull et al. 1995; Villanova et al. 1997; Glezer et al., 1998; Kim et al., 2002). NOM is often expressed in terms of total organic carbon (TOC), dissolved organic carbon (DOC), $U_{254}$ and specific UV absorbance (SUVA) (defined as $100 \mathrm{UV}_{254} / \mathrm{DOC}$ ). The NOM in natural water typically has molecular weights ranging between 500 - 5500 Dalton (Montgomery, 2005). The higher molecular weight NOM is typically hydrophobic and composed of activated aromatic rings, phenolic hydroxyl groups and conjugated double bonds, while the lower molecular weight NOM are hydrophilic and composed of aliphatic ketones and alcohols (Liang and Singer, 2003). The hydrophobic fractions of NOM has higher specific ultraviolet absorbance (SUVA) value, while the hydrophilic fractions of NOM exhibit lower SUVA value (Uyak and Toroz, 2007).

In addition, the natural water near to the coastal region contain bromide ions. Chlorination of bromide containing waters alters the reaction process and increases the fractions of brominated DBPs in the drinking waters (Uyak and Toroz, 2007). In the presence of bromide ions, chlorine forms hypobromous acid ( $\mathrm{HOBr}$ ), which is roughly 20 times more reactive with the NOM than the corresponding hypochlorous acid ( $\mathrm{HOCl})$. The increase of brominated DBPs can be attributed to the reactions of hypobromous acid ( $\mathrm{HOBr}$ ) with lower molecular weights NOM as well as a shift of chlorinated DBPs into the brominated DBPs (Liang and Singer, 2003; Uyak and Toroz, 2007). The bromide to chlorine ratio may also have an influence on the relative distributions of DBPs species in drinking water (Hellur-Grossman et al., 2001). However, depending on $\mathrm{pH}$, temperature and molecular weight distributions of NOM, only 18 to $28 \%$ of the available bromide is converted into brominated THMs, and approximately $10 \%$ of the bromide is converted into brominated HAAs (Sohn et al., 2006). Trihalomethanes (THMs) acts major proportation to DBP formation which have four compounds, namely, chloroform $\left(\mathrm{CHCl}_{3}\right)$, bromodichloromethane (BDCM), dibromochloromethane (DBCM) and bromoform $\left(\mathrm{CHBr}_{3}\right)$. 
The modeling approach efforts a predicting DBP formation potential was started in 1974 after the discovery of chloroform in chlorinated drinking waters (Bellar et al., 1974; Rook, 1974; Sadiq and Rodriguez, 2004). The first notable attempt at modeling THM formation was presented by (Trussel and Umphres, 1978), who reviewed the outcome of pre-ozonation, bromide concentration, $\mathrm{pH}$ and chlorine dose on the formation of THMs in natural waters. Multiple linear and non-linear regression technique are commonly used tool in developing DBPs predictive models (Sadiq and Rodriguez, 2004). Models for DBPs have been developed for different purposes, in some cases; modeling is aimed at identifying the significance of various operational and water quality parameters controlling the formation of DBPs or at investigating the kinetics for their mechanism. In other instances, modelling have been developed with predictive purposes as an alternative to monitoring in the field. In general, the raw water characteristics (dissolved organic carbon, $\mathrm{pH}$, and bromide concentration) and disinfection conditions (chlorine dose, temperature, reaction time) are considered as variables, which control the DBPs formation in water to a large extent, and for predicting the DBPs of water, their individual and interactive role has to be quantified. Development of reliable models is increasingly recognized as the statistical tool for predicting the DBPs formation (Rodriguez et al., 2003). Chowdhury and Champagne, (2008) reported that most of the researcher developed the model with main emphasis on NOM surrogate, chlorine dose or residual chlorine, temperature, contact time, $\mathrm{pH}$ and bromide ion concentration.

The aim of this paper is to explore the prominent precursors for prediction of TTHM during chlorination process.

\section{Materials and methods}

In order to predict the formation of THM in the treated water, a mathematical model was developed using multi linear regression (MLR) approach. THM was designated as the dependent variable, and other water quality parameters were defined as independent variables. Grab samples were collected as per standard procedures \{IS: 3025 (part1) - 1987\} from MADA water treatment as before disinfection process. The detailed analysis of various water quality parameters was carried out as per the Standard methods for analysis of water and Wastewater (APHA, 2012). Water sample was filtered through $0.45 \mu \mathrm{m}$ millipore filter paper prior to analysis for ultraviolet-absorbing organic constituents (UV254) at $254 \mathrm{~nm}$ in accordance with Standard Method 5910 B (APHA, 2012).

Total organic carbon (TOC) and DOC were analyzed by high-temperature combustion- infrared method according to Standard Method 5310 B (APHA 2012). SHIMADZU TOC-L/CSH/E200 with NDIR detector equipped with Pt catalyst was used for the determination of TOC and DOC. Total organic carbon was analyzed in unfiltered samples, whereas DOC was analyzed on filtered sample, whereas SUVA was computed as per standard ration i.e. $100 * \mathrm{UV}_{254} / \mathrm{DOC}$.

\subsection{Analysis of Trihalomethanes}

Samples were collected in pre-cleaned $40 \mathrm{ml}$ glass vials with PTFE-faced rubber septa, and quenched immediately with ascorbic acid $(25 \mathrm{mg} / 40 \mathrm{ml})$ to inhibit residual chlorine reaction. All samples were preserved at $+4{ }^{\circ} \mathrm{C}$ in the dark condition before analysis. The quantification of THMs was carried out as per USEPA method 551.1 (USEPA 1995). According to protocol, analytes (THMs) were extracted in $3 \mathrm{ml}$ of pentane during liquid-liquid extraction. The vials were shaken vigorously for $1 \mathrm{~min}$ and then kept in steady state for $3 \mathrm{~min}$ to facilitate phase separation. The aqueous phase was removed and placed in $2 \mathrm{ml}$ vials. The analysis of THMs concentration was determined using the CERES 800 plus Gas Chromatograph (Thermo Fischer) equipped with $63 \mathrm{Ni}$ ECD (Electron Capture Detector) and capillary column. Injector and detector temperatures were kept at $200{ }^{\circ} \mathrm{C}$ and $250^{\circ} \mathrm{C}$, respectively. The oven temperature was programmed to remain constant at $40{ }^{\circ} \mathrm{C}$ for $3 \mathrm{~min}$ and rise to $150^{\circ} \mathrm{C}$ at a ramp rate of $8{ }^{\circ} \mathrm{C} \mathrm{min}^{-1}$. The flow rate of nitrogen as carrier gas was maintained at $1.2 \mathrm{ml}$ $\mathrm{min}^{-1}$. Fused silica (DB-5, $30 \mathrm{~m} \times 0.32 \mathrm{~mm}$ I.D. $\times 0.30 \mu \mathrm{m}$ film thicknesses) was used as a column during analysis. 
The instrument was calibrated using analytical grade trihalomethanes standards with a purity of $>99.5 \%$. The mean recovery of four THM species ranged between $86.9 \%$ and $102.3 \%$ for this method. For the THM species, analytical procedure ensured the detection limits of $0.5 \mu \mathrm{g} \mathrm{I}^{-1}$ for chloroform and $0.3 \mu \mathrm{g} \mathrm{I}^{-1}$ for bromodichloromethane, dibromochloromethane, and bromoform.

\subsection{Quality control/quality assurance procedure ( $Q A / Q C)$}

The laboratory reagent blanks were prepared and analyzed to determine the presence of any interference in the sample. The field duplicates were used to estimate the precision of measurements. The relative percentage difference (RPD) between parallel samples was calculated and validated. In case, RPD tends to $>20 \%$ between initial samples and calibration check standard, the instrument was considered as out of calibration, and recalibrated. The method of detection limit was calculated for each compound by analyzing replicates of standard solution at a concentration of $0.25 \mathrm{\mu g} \mathrm{I}^{-1}$. Regular calibration checks were performed after analysis of every 20 samples.

\section{Results and discussion}

For development of predictive modeling approach batch study of chlorination was carried out to study the variation of only one parameter at a time while other parameters maintain a designated "baseline" condition (Table 1). The design involved dosing with chlorine (by weight) of 1-10 $\mathrm{mg} \mathrm{l}^{-1}$ and incubating for $0.5-48 \mathrm{~h} . \mathrm{pH}$ was maintained at $6.5,7.5$, or 8.5 respectively, and an incubator maintained the temperature (Temp) at 20, 24 , or $28^{\circ} \mathrm{C}$ respectively. Other water quality parameters were observed from water samples collected from MADA water treatment as before disinfection process. Collection, storage, preservation and analysis were carried out as per standard methods as discussed above.

Table 1. Orthogonal design for Batch chlorination experiments

\begin{tabular}{|c|c|c|c|c|c|c|c|c|c|c|c|c|c|c|}
\hline \multirow{2}{*}{$\begin{array}{c}\begin{array}{c}\text { Treatment } \\
\text { No. }\end{array} \\
1\end{array}$} & \multirow{2}{*}{$\begin{array}{c}\begin{array}{c}\text { Chlorine } \\
\text { dose } \\
\left(\mathrm{mg} \mathrm{l}^{-1}\right)\end{array} \\
1\end{array}$} & \multicolumn{3}{|c|}{$\mathrm{pH}$} & \multicolumn{3}{|c|}{ Temperature $\left({ }^{\circ} \mathrm{C}\right)$} & \multicolumn{7}{|c|}{ Reaction Time (in hours) } \\
\hline & & 6.5 & 7.5 & 8.5 & 20 & 24 & 28 & 0.5 & 1 & 3 & 6 & 12 & 24 & 48 \\
\hline 2 & 2 & 6.5 & 7.5 & 8.5 & 20 & 24 & 28 & 0.5 & 1 & 3 & 6 & 12 & 24 & 48 \\
\hline 3 & 4 & 6.5 & 7.5 & 8.5 & 20 & 24 & 28 & 0.5 & 1 & 3 & 6 & 12 & 24 & 48 \\
\hline 4 & 6 & 6.5 & 7.5 & 8.5 & 20 & 24 & 28 & 0.5 & 1 & 3 & 6 & 12 & 24 & 48 \\
\hline 5 & 8 & 6.5 & 7.5 & 8.5 & 20 & 24 & 28 & 0.5 & 1 & 3 & 6 & 12 & 24 & 48 \\
\hline 6 & 10 & 6.5 & 7.5 & 8.5 & 20 & 24 & 28 & 0.5 & 1 & 3 & 6 & 12 & 24 & 48 \\
\hline
\end{tabular}

In order to predict the formation of THMs in the treated water, a mathematical model was developed using MLR approach. THMs was designated as the dependent variable $(Y)$, and the water quality parameters such as TOC (X1), DOC (X2), UV254 (X3), SUVA (X4), Chlorine Dose (X5), Reaction Time (X6), Temperature (X7), and $\mathrm{pH}(\mathrm{X} 8)$ were defined as independent variables. These independent variables were selected based on the Pearson correlation matrix at $95 \%$ significance level.

\subsection{THM formation kinetics at different chlorine dose}

The result of TOC, DOC and SUVA consumption are found linear relation with respect to each other, while the value of SUVA is drastically reduced within 3 hours after the disinfection process (Figure 1 and 2). The rate of TOC, DOC and SUVA utilization were reduced to $0.469 \mathrm{mg} \mathrm{l}^{-1}, 0.463 \mathrm{mg} \mathrm{l}^{-1}$ and 0.484 , when the temperature was reduced from $28{ }^{\circ} \mathrm{C}$ to $20^{\circ} \mathrm{C}$. Result emphasis that reaction pathway of NOM is directly proportional to temperature. Nikolaou et al., (2004) also reported highest formation of TTHMS concentration at $35^{\circ} \mathrm{C}$ temperature. Williams et al., (1997) also reported that the total trihalomethane (TTHM) levels were higher in 
summer than in winter. Krasner, (1999), also showed that seasonal variations would also affect the nature of the organic precursors, which may vary in composition with the season.

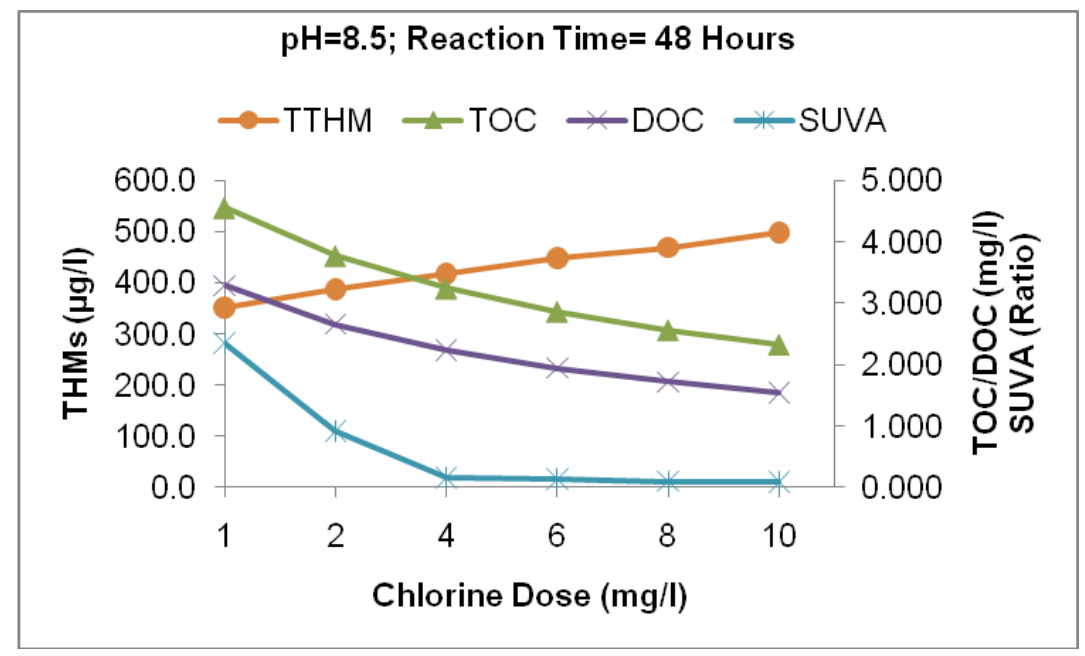

Figure 1. Interrelationship between TOC, DOC, SUVA and THM at different chlorine dose at $28^{\circ} \mathrm{C}$

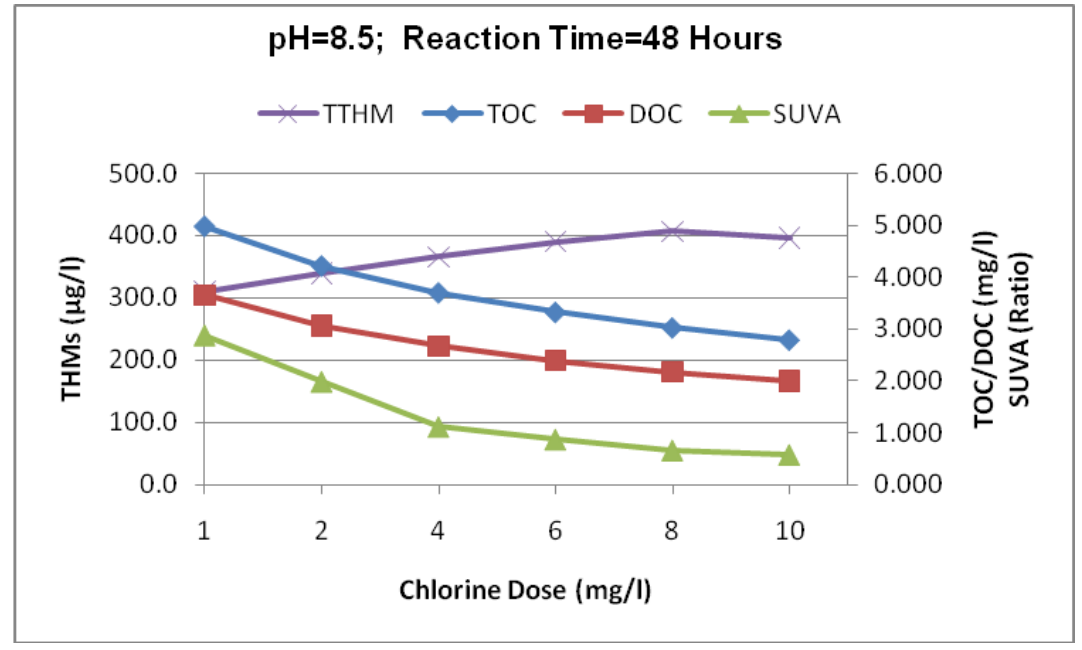

Figure 2. Interrelationship between TOC, DOC, SUVA and THM at different chlorine dose at $20^{\circ} \mathrm{C}$

\subsection{THM formation kinetics at different reaction time:}

Figure 3 and 4 show the reduction of TOC, DOC and SUVA with respect to reaction time at different temperature. The rate of TOC, DOC and SUVA utilization were reduced to $0.240 \mathrm{mg} \mathrm{l}^{-1}, 0.292 \mathrm{mg} \mathrm{l}^{-1}$ and 0.347 , when the temperature was reduced from $28{ }^{\circ} \mathrm{C}$ to $20^{\circ} \mathrm{C}$. The figures show higher specific ultraviolet absorbance (SUVA), which represents the specific structure and functional groups of organic matter content as well as an indicator of aromatic content. Higher value of SUVA indicates the organic matter in the source waters contains more hydrophobic fractions of NOM. Hydrophobic fractions are generally composed of the higher molecular weight NOM with activated aromatic rings, phenolic hydroxyl groups and conjugated double bonds. The value of SUVA is decreasing with respect to temperature and reaction time, which reveled higher rate of utilization for hydrophobic fractions of NOM. Values of SUVA is drastically reduced with respect to higher chlorine dose which represent the chlorine contact is more predominant with hydrophobic fractions of NOM. Childress et al., 1999 reported that the humic fractions of NOM (indicated by a value of SUVA > 4) 
have high THMs formation potential while raw waters with SUVA below 3 (less humic content) have low THMs formation potential.

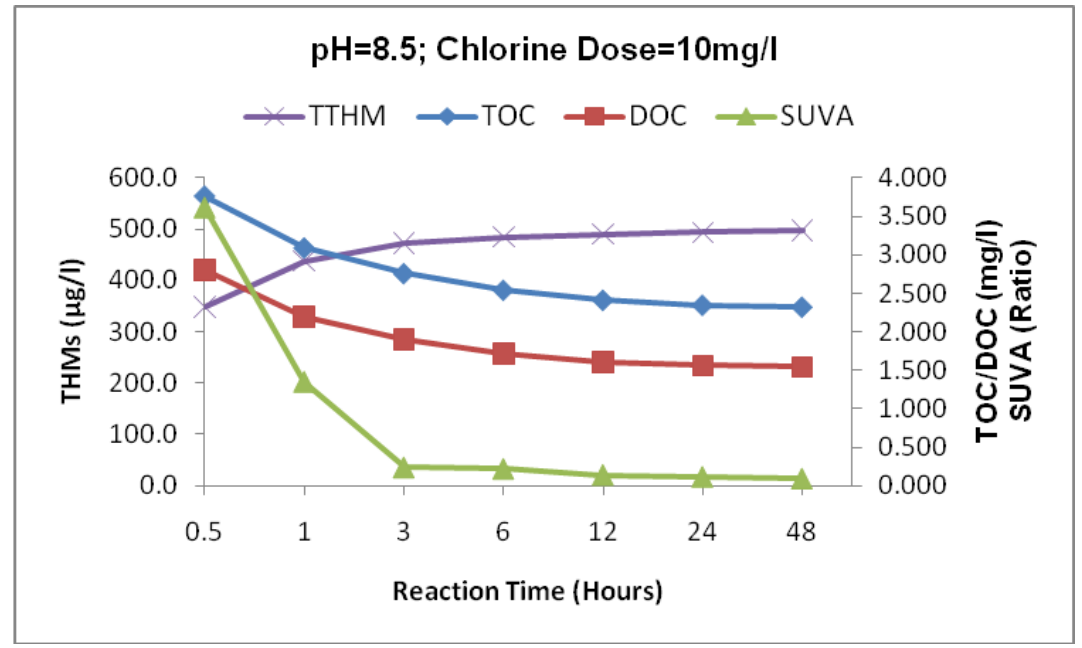

Figure 3. Interrelationship between TOC, DOC, SUVA and THM at different reaction time at $28^{\circ} \mathrm{C}$

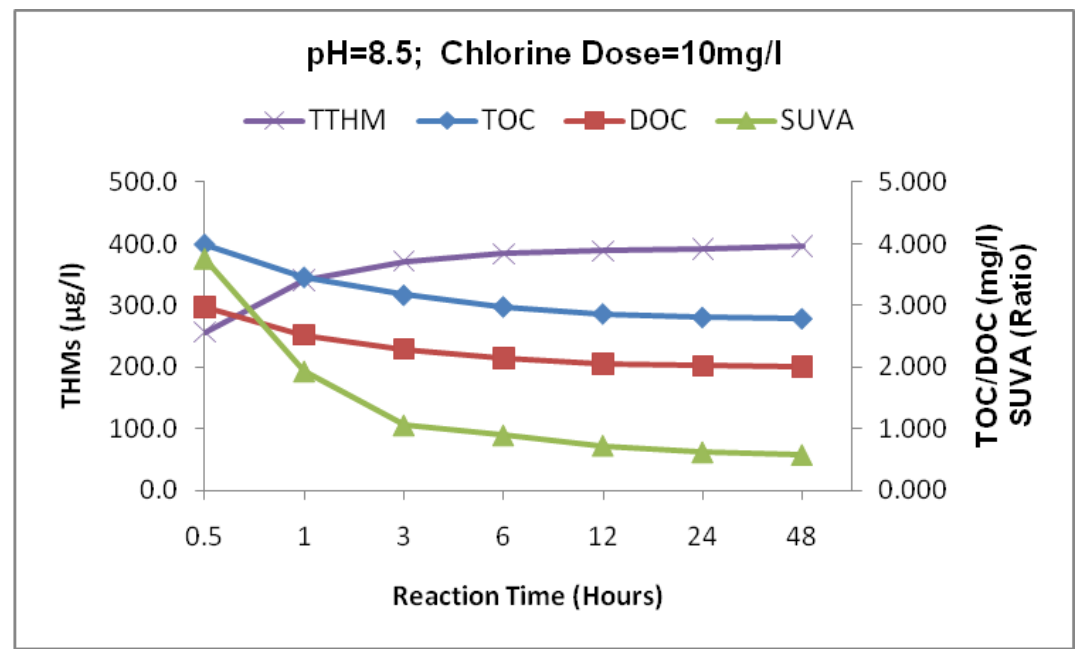

Figure 4. Interrelationship between TOC, DOC, SUVA and THM at different reaction time at $20^{\circ} \mathrm{C}$

\subsection{THM formation kinetics at different $\mathrm{pH}$}

Results revealed that temperature plays important role in the disinfection process for long range of $\mathrm{pH}$ variability. The rate of THM formation increases up to $51.3 \mu \mathrm{g} \mathrm{l^{-1 }}$ when the $\mathrm{pH}$ increases from 6.5 to 8.5 at $28{ }^{\circ} \mathrm{C}$ after 48 hour disinfection process (fig 5-6). The outcome revealed that THM reaction pathway due to alkaline condition of water is more predominant than acidic condition as well as higher temperature. Many more scientists and researcher (Stevens et al., 1976; Oliver and Lawrence, 1979; Kim et al., 2002) reported that the increase in $\mathrm{pH}$ has an important effect on the formation of THMs which increase with increase in $\mathrm{pH}$. Peters et al., 1980 and Sandler et al., (1977) concluded the same trend of the study that the formation of THMs depends mainly on the final step of THM reaction pathway, which is the base - catalyst as with the haloform reaction. Under alkaline conditions, base catalyzed hydrolysis prevails, yielding more THMs while in acidic environments, trihaloacetic acids will be formed. Results indicate that more than $95 \%$ percentage of chloroform found in this discipline which can be attributed to alkaline $\mathrm{pH}$ of water and low level of bromide 
concentration as well as the intermediate chlorinated organics formation during the disinfection process. Morris and Bawn, (1978) reported same trend formation of higher chloroform.

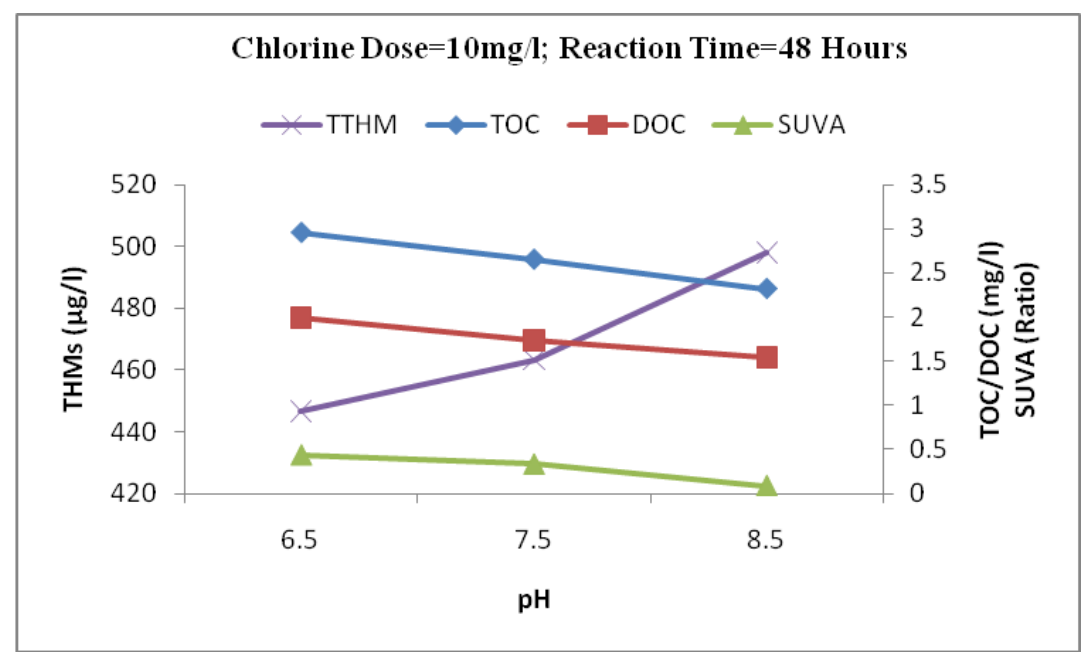

Figure 5. Interrelationship between TOC, DOC, SUVA and THM at different $\mathrm{pH}$ at $28^{\circ} \mathrm{C}$

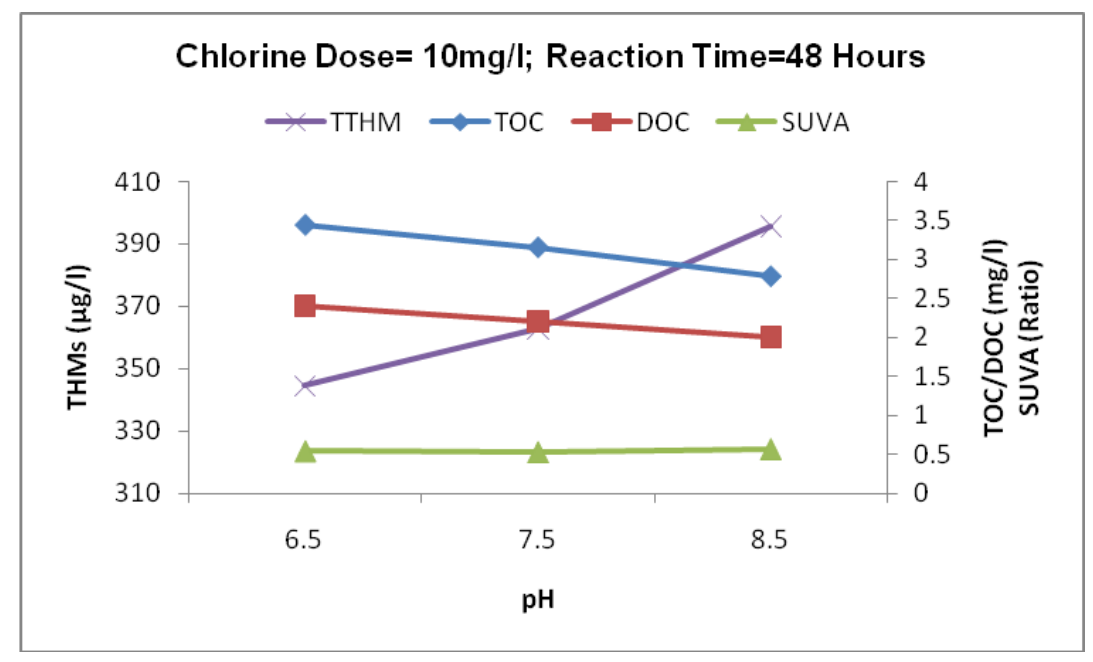

Figure 6. Interrelationship between TOC, DOC, SUVA and THM at different $\mathrm{pH}$ at $20^{\circ} \mathrm{C}$

Several authors (Morris and Baum, 1978; Stevens et al., 1976; Fleischacker and Randtke, 1983; Reckhow and Singer, 1985) observed that the chlorination of most of organic compounds led to large quantities of chloroform at higher $\mathrm{pH}$ values. Similar correlations between $\mathrm{pH}$ and THMs were also showed by other researchers (Peters et al., 1980, Kavanaugh et al., 1980, Uyak et al., 2005 and Elsheikh and Basiouny, 2011).

\subsection{Development of multiple linear regressions $(M L R)$ model}

Multivariate regression analysis was conducted to develop statistical models for predicting DBPs based on water quality and operational parameters. Predictive modeling approach was developed considering different combination of NOM surrogates, operational condition of disinfection process as well as water quality characteristics. The correlation between operational parameters and THMs concentration have been represented in table no.2. The relationships between the measured and predicted values were satisfactory (fig 7 to 11) with $R^{2}$ values ranging from 0.927 to 0.937 compared with other THM formation models with $\mathrm{R}^{2}$ values ranging between 0.34 and 0.99 (Watson, 1993; Abdullah et al., 2003; Sadiq and Rodriguez, 2004). 
Table 2. List of predictive models for THMs formation

\begin{tabular}{cc}
\hline S.No & Description of Model \\
\hline 1. & TTHMs $=488.511+3.042(\mathrm{pH})+1.921(\mathrm{~T})-0.114(\mathrm{t})+5.580(\mathrm{D})-13.405(\mathrm{RC})-56.783(\mathrm{DOC})-20.311(\mathrm{SUVA})$ \\
\hline 2. & $\mathrm{TTHMs}=768.045-3.816(\mathrm{pH})+0.347(\mathrm{~T})+0.091(\mathrm{t})-0.555(\mathrm{D})-12.882(\mathrm{RC})-43.922(\mathrm{DOC})-60.396(\mathrm{TOC})$ \\
\hline 3. & $\mathrm{TTHMs}=415.396+2.914(\mathrm{pH})+2.129(\mathrm{~T})-0.129(\mathrm{t})+9.397(\mathrm{D})-17.753(\mathrm{RC})-22.872(\mathrm{TOC})-802.214(\mathrm{UV} 254)$ \\
\hline 4. & $\mathrm{TTHMs}=378.483+4.490(\mathrm{pH})+2.125(\mathrm{~T})-0.120(\mathrm{t})+10.318(\mathrm{D})-18.201(\mathrm{RC})-814.503(\mathrm{UV} 254)-24.295(\mathrm{DOC})$ \\
\hline 5. & $\mathrm{TTHMs}=558.528-0.275(\mathrm{pH})+1.984(\mathrm{~T})-0.134(\mathrm{t})+4.078(\mathrm{D})-12.841(\mathrm{RC})-50.635(\mathrm{TOC})-20.001(\mathrm{SUVA})$ \\
\hline
\end{tabular}

TTHMs = Total Trihalomethane $\left(\mu \mathrm{g} \mathrm{l}^{-1}\right) ; T=$ Temperature $\left({ }^{\circ} \mathrm{C}\right) ; t=$ Reaction Time (Hours); $D=$ Chlorine Dose $\left(\mathrm{mg} \mathrm{l} \mathrm{l}^{-1}\right) ; \mathrm{RC}=\mathrm{Residual}$ Chlorine (mg l-1); TOC= Total Organic Carbon $\left(\mathrm{mg} \mathrm{l}^{-1}\right) ; D O C=$ Dissolved Organic Carbon (mg l-1); UV $254=$ UV absorbance at $254 \mathrm{~nm}$ wavelengths; SUVA= specific ultraviolet absorbance [L/(mg-m)]

All MLR models are generated with two surrogates of NOM with multiple selection of NOM variable, which included a combination of TOC-DOC, TOC-SUVA, TOC-UV 254 , DOC-SUVA and DOC-UV 254.

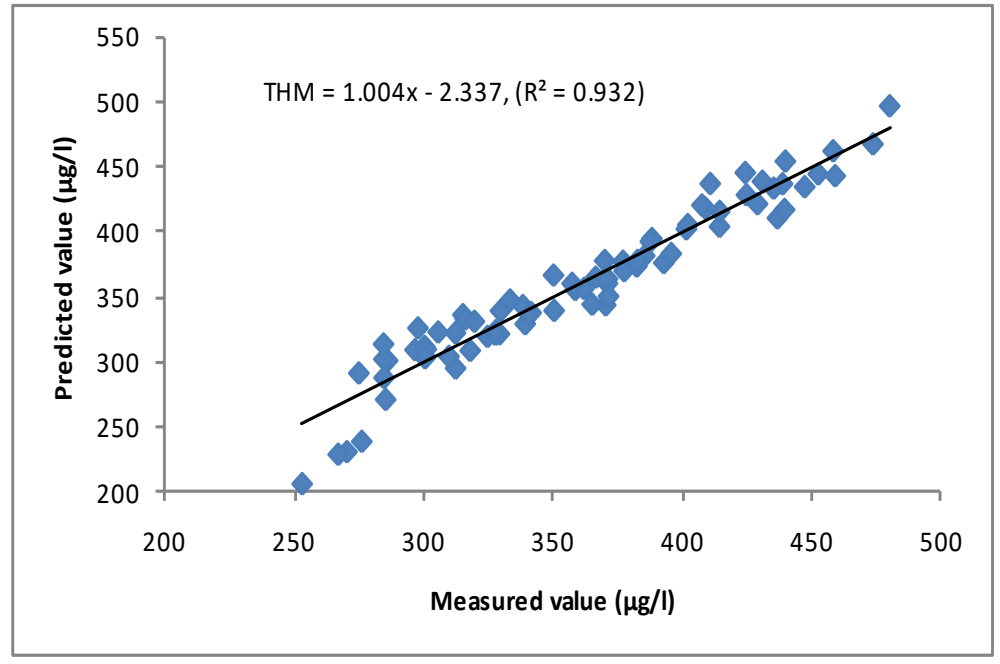

Figure 7. Prediction of TTHMs by MLR model with two surrogates of NOM (DOC \& SUVA)

The predictive level of THM concentration is generated with above model are in the range of over to below prediction, $52.5 \%$ of the predicted values observed in over range whereas $47.5 \%$ values shows THM concentration below the assessed value. Over prediction of THM values varies between 0.8 to $46.2 \mu \mathrm{g} \mathrm{I}^{-1}$ and the values for below prediction varies between 5.6 to $29.9 \mu \mathrm{g} \mathrm{I}^{-1}$. The $\mathrm{R}^{2}$ value of the model shows a good performance for the prediction of THM concentration levels in drinking water at each stage of the procedure. $25.6 \%$ of the predicted values vary only in the range of $\pm 05 \mathrm{\mu g} \mathrm{I}^{-1}$ to measure value of THM concentration.

All THM concentration predicted by the above given model found over prediction level. Over prediction of THM values varies between 17.5 to $52.6 \mathrm{\mu g}^{-1}$, but $65 \%$ of the predicted values are found over prediction in the range of 25 to $52.6 \mu \mathrm{gl}^{-1}$. Only $5.1 \%$ of the predicted values vary only in the range of $\pm 20 \mu \mathrm{g} \mathrm{I}^{-1}$ to measure value of THM concentration. Whereas the $R^{2}$ value of prediction level was found 0.927 which is minimum $R^{2}$ found any prediction observation in the proposed model. The outcome revealed that TOC \& DOC play an important role for predictive modeling approach, but water having high aromatic content always required the incorporation of aromatic indicator of like UV254 or SUVA.

The predictive values of THM concentration are generated with the model as shown in fig. 9 are in the range of over to below a prediction, the level of over and below prediction were found a same trend line as model discussed in fig. 7 and 8. 


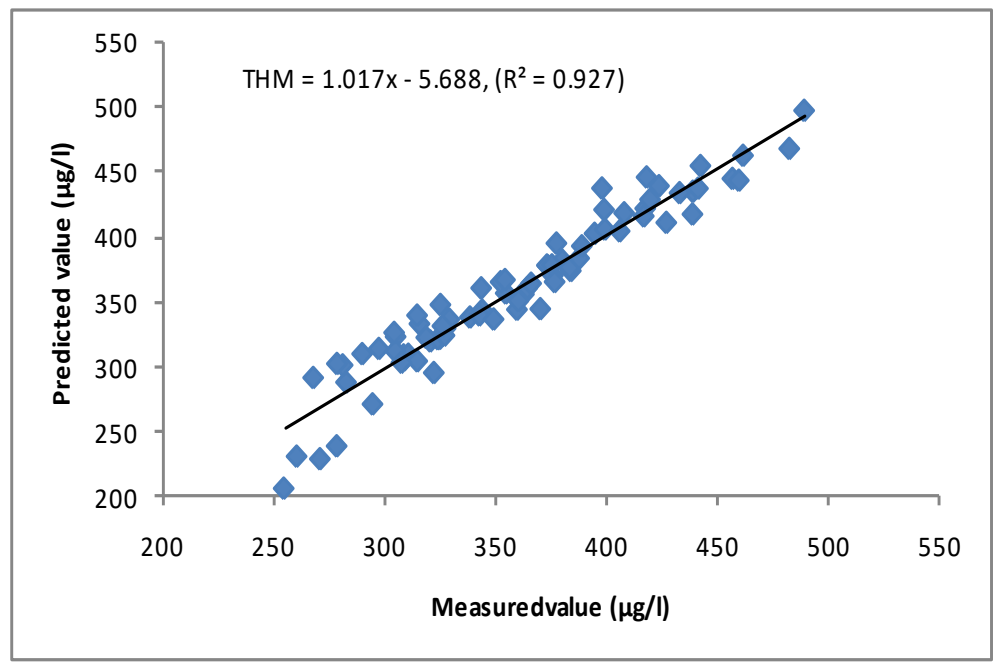

Figure 8. Prediction of TTHMs by MLR model with two surrogates of NOM (DOC \& TOC)

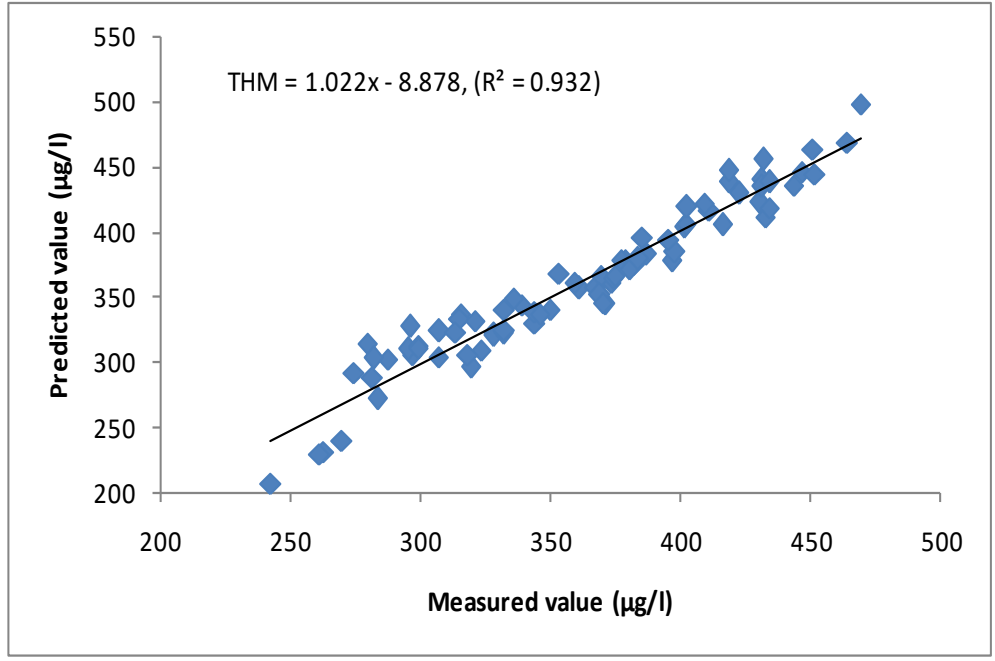

Figure 9. Prediction of TTHMs by MLR model with two surrogates of NOM (TOC \& UV $\left.{ }_{254}\right)$

Predicted values observed in over range were found in the range of $52.5 \%$, whereas $47.5 \%$ values show THM concentration below the assessed value. Over prediction of THM values varies between 0.6 to $36.2 \mu \mathrm{g} \mathrm{I}^{-1}$ and the values for below prediction varies between 1.4 to $34.2 \mathrm{\mu g} \mathrm{I}^{-1}$. The R2 value of the model shows a good performance for the prediction of THM concentration levels in drinking water at each stage of the procedure. $20.5 \%$ of the predicted values vary only in the range of $\pm 05 \mathrm{\mu g} \mathrm{I}^{-1}$ to measure value of THM concentration.

The predictive level of THM concentration is generated with above model are in the range of over to below prediction, $52.5 \%$ of the predicted values observed in over range whereas $47.5 \%$ values shows THM concentration below the assessed value. Over prediction of THM values varies between 1.1 to $37.7 \mu \mathrm{g} \mathrm{I}^{-1}$ and the values for below prediction varies between 1.3 to $34 \mu \mathrm{g} \mathrm{I}^{-1}$. The $\mathrm{R}^{2}$ value of the model shows a good performance for the prediction of THM concentration levels in drinking water at each level of the process. $16.6 \%$ of the predicted values vary only in the range of $\pm 05 \mathrm{\mu g} \mathrm{I}^{-1}$ to measure value of THM concentration. 


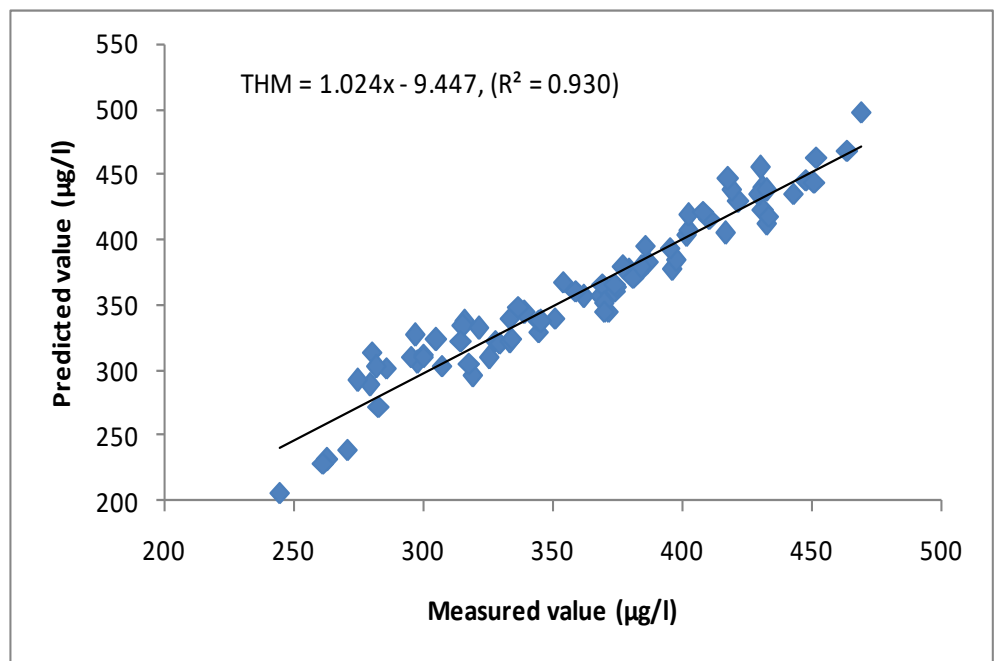

Figure 10. Prediction of TTHMs by MLR model with two surrogates of NOM (UV 254 \& DOC)

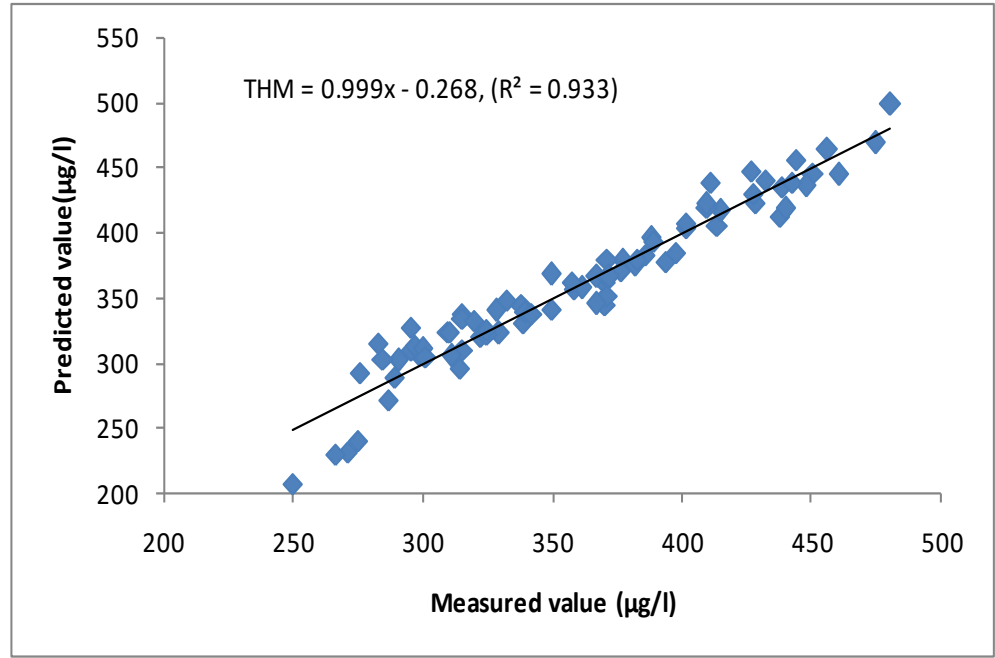

Figure 11. Prediction of TTHMs by MLR model with two surrogates of NOM (TOC \& SUVA)

The predictive values of THM concentration are generated with the model as was found in the range of over to below a prediction, the level of over and below prediction were found a same trend line as above model discussed model. Predicted values observed in over range were found in the range of $52.5 \%$, whereas $47.5 \%$ values show THM concentration below the assessed value. Over prediction of THM values varies between 0.5 and $42.9 \mathrm{mg} \mathrm{l}^{-1}$ and the values for below prediction varies between 0.3 to $31.9 \mathrm{\mu g}^{-1}$. The $\mathrm{R}^{2}$ value of the model shows a good performance for the prediction of THM concentration levels in drinking water at each stage of the procedure. $28.2 \%$ of the predicted values vary only in the range of $\pm 05 \mu \mathrm{gl}^{-1}$ to measure value of THM concentration.

\subsection{Prediction of THMs concentration by single surrogates of NOM}

Prediction of THMs is also carried out by the model developed by Serodes et al. (2003), the model used for prediction of THM concentration was made by the regression method through bench-scale chlorination experiments using treated water (prior to final chlorination) from three major drinking water utilities in Quebec (Canada). The $\mathrm{R}^{2}$ value 0.484 shows poor correlation, while predicting the THMs concentration in 
drinking water in the present study area, the prediction range was varied minimum 17.53 to maximum 52.64 , which implies that this model cannot be used in the proposed study area. The results also revealed that model developed by Serodes et al. (2003) not incorporated the pH as well as more surrogates of natural organic matter, which reduces the performance of model in another part. The present study area has high content of aromatic content in water, which requires a valid training and testing of the data with present conditions.

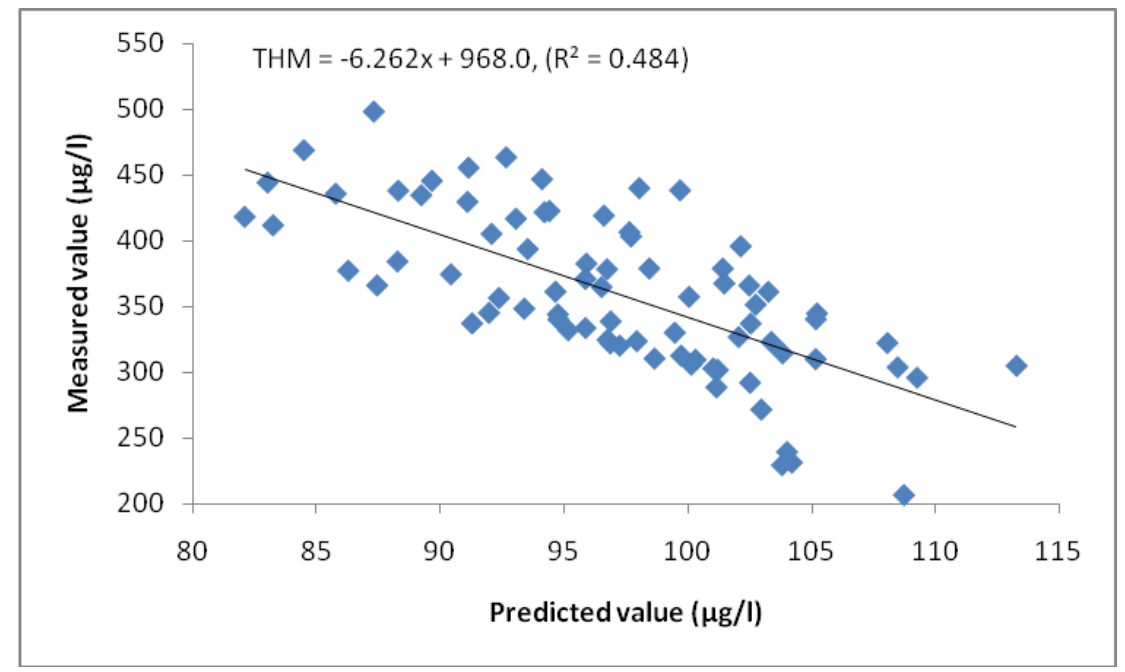

Figure 12. Prediction of THMs concentration by Serodes et al. (2003) model $[$ THMs $=16.9+16.0(T O C)+3.319$ (D) $-1.135(\mathrm{~T})+1.139(\mathrm{t})]$

\section{Conclusions}

THMs in drinking water were monitored in laboratory condition with a variance of only one parameter at a time while other parameters maintain a designated "baseline" condition. Concentration of THMs was found in the range of ( 189.4 to $498.0 \mathrm{\mu g} \mathrm{I}^{-1}$ ) in drinking water with set of combination test. The variation in TTHM concentration among attributed to varying condition like chlorine dose, $\mathrm{pH}$, temperature and reaction time.

Amongst the various THMs, the concentration of chloroform was found highest (185.7 to $491.6 \mu \mathrm{g} \mathrm{I}^{-1}$ ) and exceeded the permissible USEPA (2011) standard/guideline values ( $80 \mathrm{ppb}$ ) in all set of experiments. Whereas limit of WHO (2011) and IS 10500 (2012) shows that chloroform concentration lies in prescribed limit 300 $\mu \mathrm{g} \mathrm{I}^{-1}$ in some of the characters. The concentration of other THMs i.e. dichlorobromomethane $(\mathrm{CHBrCl} 2)$ and dibromochloromethane $(\mathrm{CHBr} 2 \mathrm{Cl})$ were found to be very less as compared to their prescribed standards by USEPA (2011), WHO (2011) and IS 10500 (2012). Due to non coastal zone of selected area the bromoform was not detected water sample. The study depicted that amongst various THMs, the contribution of chloroform was highest (97.99 to $98.71 \%)$. Higher values of $U V_{254}\left(>0.1 \mathrm{~cm}^{-1}\right)$ and SUVA $3(>3)$ found in the drinking water indicated that humic content i.e. Humic and fulvic acids in the natural organic matter are very high compared to the non-humic fraction which reveled high aromatic content in water. A strong correlation of UV254 with THMs \& TOC also indicate the predominance of aromatic content of organic matter in the water, which are normally not taken away from the conventional treatment processes and contribute to the formation of THMs in drinking water. A high and significant correlation was observed between $\mathrm{pH}$ and TTHMs indicating that the TTHMs increased with increasing $\mathrm{pH}$ showing THM formation reaction rate are catalyzed in alkaline $\mathrm{pH}$. Very strong and substantial correlation of the temperature with THMs indicated that temperature significantly enhances the rate of THMs formation and effects are more visualized especially during summer when the temperature is high. 
The empirical models for THMs, took into consideration the parameters indicating the raw water quality and chlorination condition, and showed that they were sensitive in predicting THM formation. All models show high $\mathrm{R}^{2}$ value in each best fitted model, which revealed that the kinetics of THM formation follows the linear relationship for water quality characteristics and operational condition of disinfection during THM formation. $\mathrm{R}^{2}$ values are varied with respect selection variable of NOM. Fig 7 to 11 shows that $U_{254}$ and SUVA incorporation in modeling gives better performance rather than TOC and DOC selection, which revealed that aromatic content indicator ( $\mathrm{UV}_{254}$ and SUVA) shows higher and close performance of any model. Most of the researchers also found that selection $U_{254}$ and SUVA increases the performance of the model with respect to other variables. All figures show that the measured and predicted values of THM are closed, especially in the middle range of concentration, which revealed that the kinetics of THM formation is extremely linear with respect to middle range of reaction time.

\section{References}

Becher G. (1999), Drinking water chlorination and health, Acta Hydrochem Hydrobiol., 27, 100-102.

Bellar T.A., Lichtenberg J.J. and Kroner R.C. (1974), The occurrence of organohalides in chlorinated drinking waters, J Am Water Works Assoc, 66(12), 703-706.

Bull R.J., Birnbaum L.S., Cantor K.P., Rose J.B., Butterworth B.E., Pegram R. and Tuomisto J. (1995), Water chlorination: Essential process or cancer hazard?, Fundam Appl Toxicol, 28(2), 155-166.

Calderon R. L. (2000), The epidemiology of chemical contaminants of drinking water, Food and Chemical Toxicology, 38, (1Suppl), S13-20.

Childress A.E., Vrijenhoek E.M., Elimelec M., Tanaka, T.S. and Beuhler M.D. (1999), Particulate and THM precursor removal with ferric chloride, J. Environ. Eng., 125(11), 1054- 1061.

Chlorine Chemistry Council (2003), Drinking water chlorination: a review of disinfection practices and issues, Arlington, VA.

Chowdhury S. and Champagne P. (2008), An investigation on parameters for modeling THMs formation, Global NEST Journal, 10(1), 80-91.

Edzwald J K. and Tobiason J. E. (1999), Enhanced Coagulation: US Requirements and a Broader View, Water Science and Technology, 40(9), 63-70.

Elsheikh M.A. and Basiouny M.E. (2011), Deposition and formation of THMS in water supply system, Sustain. Environ. Res., 21(2), 89-94.

Fleischaker S.J. and Randtke S.J. (1983), Formation of organic chlorine in public water supplies, Journal of American Water Work Association, 75(10), 132-138.

Gallard H. and Von G.U. (2002), Chlorination of natural organic matter: kinetics of chlorination and of THM formation, Water Research, 36(1), 65-74.

Garcia-Villanova R.J., Garcia C., Cesar Gomez J.A., Garcia M.P. and Ardanuy R. (1997b), Formation, evolution and modeling of trihalomethanes in the drinking water of a town: II. In the distribution system, Water Research, 31(6), 1405-1413.

Glezer V., Harris B., Tal N., losefzon B. and Lev O. (1999), Hydrolysis of haloacetonitriles: linear free energy relationship, kinetics and products, Water Research, 33(8), 1938-1948.

Golfinopoulos S.K. and Arhonditsis G.B. (2002), Multiple regression models: A methodology for evaluating trihalomethane concentrations in drinking water from raw water characteristics, Chemosphere, 47(9), 1007-1018.

Golfinopoulos S.K., Xilourgidis N.K., Kostopoulou M.N. and Lekkas T.D. (1998), Use of a multiple regression for predicting trihalomethane formation, Water Research, 32(9), 2821-2829. 
Hellur G.L., Manka J., Lamoni R.B. and Rebhun M. (2001), THM, haloacetic acids and other organic DBPs formation in disinfection of bromide rich Sea of Galilee (Lake Kinneret) water, Water Science and Technology: Water Supply, 1(2), 259-266.

IARC (1991), Chlorinated drinking water chlorination byproduct: some other halogenated compounds cobalt and cobalt compounds, IARC Monographs on Evaluation of Carcinogenic Risks in Humans, 52, 179-212.

Kavanaughet M.C., Trussell A.R., Cromer J. and Trussell R.R. (1980), An empirical kinetic model of Trihalomethane formation-Applications to meet the proposed THM standard, Journal AWWA, 11, 578-582.

Kim J., Chung Y., Shin D., Kim M., Lee Y., Lim Y. and Lee D. (2003), Chlorination by-products in surface water treatment process, Desalination, 151, 1-9.

Krasner S.W. (1999), Chemistry and occurrence of disinfection by-products. Abstract Commun. Second International Conf. on the Safety of Water Disinfection: Balancing Chemical and Microbial Risks, November 15-17, Miami Beach, FL In: Safety of Water Disinfection: Balancing Chemical and Microbial Risks, 57-59.

Liang L. and Singer P.C. (2003), Factors influencing the formation and relative distribution of haloacetic acids and trihalomethanes in drinking water, Environ. Sci. Technol, 37(13), 2920-2928.

Mills C.J., Bull R.J., Cantor K.P., Reif J., Hnidey S.E. and Huston P. (1998), Health Risks of Drinking Water Chlorination ByProducts: Report of An Expert Working Group, Health Canada-CDIC, 19(3), 91-102.

Montgomery W.H. (2005), Water Treatment: Principles and Design. John Wiley \& Sons, NJ.

Morris J.C. and Baum B. (1978), Precursors and mechanism of haloform formation in the chlorination of water supplies, Water Chlorination: Environmental Impact and Health Effects (2). Ann Arbour Science Publisher.

Nikolaou A.D., Lekkas T.D. and Golfinopoulos S.K. (2004), Kinetics of the formation and decomposition of chlorination by-products in surface waters, Chemical Engineering Journal, 100(1), 139-148.

Oliver B.G. and Lawrence S. (1979), Haloforms in drinking water: A study of precursors and precursor removal, JAWWA, 71(3), 161-163.

Parsons S.A., Jefferson B., Goslan E.H., Jarvis P.R. and Fearing D.A. (2005), Natural organic matter - The relationship between character and treatability, Water Science and Technology, Water Supply, 4(5-6), 43-48.

Peterborough Utilities Commission (1998), http://www.puc.org/hist.htm.

Peters C.J., Young R.J. and Perry R. (1980), Factors influencing the formation of Haloforms in the chlorination of humic materials, Environ Sci Technol, 14(11),1391-1395.

Pontius F.W. (1999), Complying with future water regulations, J. Am. Water Works Assoc, 91, 46-58.

Reckhow D.A. and Singer P.C. (1985), Mechanism of organic halide formation during fulvic acid chlorination and implication respect to preozonation. In Water Chlorination Chemistry: Environmental Impact and Health Effect. Vol 5. Lewis Publisher.

Richardson S.D., Simmons J.E. and Rice G. (2002), Disinfection byproducts: the next generation, Environmental Science and Technology, 36(9), 198-205.

Rodriguez M.J., Vinette Y., Serodes J.B. and Bouchard C. (2003), Trihalomethanes in drinking water of greater Quebec region (Canada): occurrence, variations and modeling, Environ Monit Assess, 89(1),69-93.

Sadiq R. and Rodriguez M. (2004), Disinfection byproducts (DBPs) in drinking water and predictive models for their occurrences: a review, Science of the Total Environment, 321(1), 21-46.

Sandler R. (1977), Investigations on the construction of organic chlorinated compounds of both chlorides of water containing humic acid, Thesis Ph.D. Engler-Bunte Institute, University of Karlsruhe. (In German)

Serodes J.B., Rodriguez M.J., Li H. and Bouchard C. (2003), Occurrence of THMs and HAAs in experimental chlorinated waters of the Quebec City area (Canada), Chemosphere, 51(4),253 - 263.

Sohn J., Amy G., Cho J., Lee Y. and Yoon Y. (2004), Disinfectant decay and disinfection by-products formation model development: chlorination and ozonation by-products, Water Research, 38(10), 2461-2478.

Stevens A.A., Slocum C.J., Seeger D.R. and Robeck G.B. (1976), Measurement of THM and precursor concentration changes, Journal of American Water Works Association, 68, 546-554. 
Trussel R.R. and Umphres M. (1978), The formation of Trihalomethanes, J Am Water Works Assoc, 70(11), 604-612.

Trussell R.R. (1993), Treatment for the control of disinfection residuals and disinfection by products, in: G.F. Craun (Ed.), Safety of Water Disinfection: Balancing Chemical and Microbial Risks, International Life Sciences Institute Press, Washington, 319-343.

Uyak V. and Toroz I. (2007), Investigation of bromide ion effects on disinfection by-products formation and speciation in an Istanbul water supply, J Hazardous Material, 149(2), 445-451.

Uyak V., Toroz I. and Meric S. (2005), Monitoring and modeling of trihalomethanes (THMs) for a water treatment plant in Istanbul, Desalination, 176(1), 91-101.

Villanueva C.M., Cantor K.P., Cordier S., Jaakkola J.J.K., King W.D., Lynch C.F., Porru S. and Kogevinas M. (2004), Disinfection Byproducts and Bladder Cancer: a Pooled Analysis, Epidemiology, 15(3), 357-367.

Volk C., Bell K., Ibrahim E., Verges D., Amy G. and Lechevallier M. (2000), Impact of enhanced and optimized coagulation on removal of organic matter and its biodegradable fraction in drinking water, Water Research, 34(12), 3247-3257.

Williams D., LeBel G.L. and Benoit F. (1997), Disinfection by-products in Canadian drinking water, Chemosphere, 34(2), 299-316. 